\section{G505 VERTICAL INTEGRATION IN NHS PAEDIATRIC CARE: A QUALITATIVE EXPLORATION OF BARRIERS AND ENABLERS}

${ }^{1} E J$ Maile, ${ }^{2} S$ Machen, ${ }^{3} D$ D'Lima, ${ }^{2} \mathrm{G}$ Black. ${ }^{1}$ Department of Primary Care and Public Health, Imperial College London, London, UK; ${ }^{2}$ Department of Applied Health Research, UCL, London, UK; ${ }^{3}$ Department of Clinical, Educational and Health Psychology, UCL, London, UK

\subsection{6/archdischild-2020-rcpch.430}

Aims Vertical integration describes primary and secondary care working closely together to provide joined-up healthcare services for patients. There have been attempts to vertically integrate paediatric services since the $1950 \mathrm{~s}$, but these have been routinely de-implemented due to shifting managerial and commissioning priorities. Recently, the NHS Long Term Plan articulated a renewed aspiration to vertically integrate paediatric services. This study aims to characterise the barriers and enablers to vertically integrating paediatric services, and to contextualise these within current NHS policy to produce meaningful insights for clinicians, managers and policymakers.

Methods Participants were selected using purposive sampling. Twenty-two paediatric professionals (16 paediatricians, 3 GPs, 2 nurses and 1 commissioner) were selected, who had experience of integrated care and were in the latter stages of their career. Semi-structured interviews were performed focussing on their experiences of vertical integration in paediatrics. Transcripts were thematically analysed to identify barriers and enablers to vertical integration. Themes were ordered into three categories: (1) factors affecting individuals, (2) factors relating to local policy or management and (3) factors relating to national policy or politics.

Results At individual level, barriers included: (i) Clinicians' skills, including discomfort of some paediatricians with the risk in primary care and some GPs lacking detailed paediatric knowledge, and (ii) a lack of time in clinicians' schedules for collaborative work. Enablers included: (i) Strong relationships between primary and secondary care clinicians; (ii) good communication between clinicians and (iii) co-location of clinicians' working environments. At local level, barriers included (i) perceptions that managers lacked knowledge of vertical integration; (ii) a perceived lack of evidence to support vertical integration; and (iii) restrictive organisational structures. At a national level, barriers included (i) perceptions that the public and politicians viewed hospitals as the ultimate goal of healthcare, impeding efforts to move or share resources; and (ii) a perceived lack of value placed on children by broader society.

Conclusions Our findings highlight that vertically integrating paediatric services requires overcoming barriers at multiple levels. We also describe some enablers of integration. These findings are highly relevant in the current policy environment and will be instructive to clinicians, managers and policymakers involved in integrating services in the future.

\section{G506 CAN A PAIRED LEARNING PROGRAMME IMPROVE DOCTOR-MANAGER RELATIONSHIPS?}

${ }^{1} \mathrm{~J}$ Houston, ${ }^{2} \mathrm{~J}$ Morgan. ${ }^{1}$ Paediatrics, York Teaching Hospital NHS FT, York, UK; ${ }^{2}$ Centre for Reviews and Dissemination, University of York, York, UK

10.1136/archdischild-2020-rcpch.431

Aims Effective collaboration between doctors and managers is essential, however, relationships between these two groups are often strained. Paired Learning joins doctors and managers together to facilitate collaboration by learning about each other. This project aimed to explore the impact of the Paired Learning Programme (PLP) on knowledge, attitudes, and relationships between doctors and managers.

Methods The PLP consisted of two group meetings to explore key issues and four doctor-manager partner meetings to facilitate learning via informal conversation based around a topic guide. Knowledge and attitudes were assessed using pre and post-course questionnaires and relationships were assessed during focus groups, which were audio recorded and analysed with ethnographic notes from the researchers.

Results Six Managers and six Doctors were recruited. All twelve completed the programme. After the PLP, mean selfrated domains for attitudes and knowledge increased significantly in all six domains (see table 1). Participants reported improved understanding and relationships. Doctors demonstrated improved attitudes towards managers. Focus group themes were conflict, lack of understanding and participants demonstrated better interaction after the PLP.

\begin{tabular}{|c|c|c|c|}
\hline Question & $\begin{array}{l}\text { Pre-course mean } \\
\text { (95\% confidence } \\
\text { interval) } N=12\end{array}$ & $\begin{array}{l}\text { Post-course mean } \\
\text { (95\% confidence } \\
\text { interval) } N=12\end{array}$ & $\begin{array}{l}P \\
\text { value }\end{array}$ \\
\hline $\begin{array}{l}\text { 1) I am aware of the role of } \\
\text { doctors/managers. }\end{array}$ & $3.42(2.80-4.03)$ & $4.33(4.05-4.61)$ & 0.009 \\
\hline $\begin{array}{l}\text { 2) I am able to engage with } \\
\text { doctors/managers. }\end{array}$ & $3.25(2.61-3.89)$ & $4.5(4.20-4.80)$ & 0.006 \\
\hline $\begin{array}{l}\text { 3) I am able to establish shared } \\
\text { goals with doctors/managers. }\end{array}$ & $3.00(2.46-3.54)$ & $4.08(3.57-4.59)$ & 0.030 \\
\hline $\begin{array}{l}\text { 4) I am aware of the clinical/ } \\
\text { managerial decision-making } \\
\text { process. }\end{array}$ & $2.83(2.30-3.36)$ & $4.08(3.92-4.25)$ & 0.002 \\
\hline $\begin{array}{l}\text { 5) I have a positive regard for } \\
\text { doctors/managers. }\end{array}$ & $4.08(3.71-4.46)$ & $4.67(4.39-4.95)$ & 0.027 \\
\hline $\begin{array}{l}\text { 6) I have developed a 'professional } \\
\text { network' to support my clinical and } \\
\text { non-clinical/professional activities. }\end{array}$ & $2.83(2.20-3.46)$ & $4.25(3.99-4.51)$ & 0.003 \\
\hline
\end{tabular}

Discussion/Conclusion This study provides evidence that paired learning may improve communication and relationships between doctors and managers. Paired Learning should be considered as an organisational tool to facilitate better doctormanager relationships.

\section{G507 COMPLEX CARE ATTENDING MODEL}

${ }^{1} \mathrm{~S}$ Roberts, ${ }^{1} \mathrm{R}$ Ramachandran, ${ }^{2} \mathrm{~J}$ Gough, ${ }^{3} \mathrm{C}$ Wicks, ${ }^{1} \mathrm{M}$ Butler, ${ }^{1} \mathrm{R}$ Cheung, ${ }^{1} \mathrm{~B}$ Tiesman, ${ }^{1}$ I Cockar. 'General Paediatrics, Evelina London Children's Hospital, London, UK; ${ }^{2}$ Service Improvement Team, Evelina London Children's Hospital, London, UK; ${ }^{3}$ Community Paediatrics, Evelina London Children's Hospital, London, UK

\subsection{6/archdischild-2020-rcpch.432}

Aim Our current working paediatric model is based around a rapid turnover of acutely unwell children with none or limited co-morbidities, who are expected to return to prior health with appropriate medical management. In order to fulfil these 
standards we operate a weekly attending consultant system with resident on calls until 9pm, with a focus on acutely unwell children including fulfilling standard of consultant review of acute admission within 14 hours of admission. We have increasingly realised that this model of care in insufficient to care effectively for patients with more complex medical and social health needs.

We are to piloting a new model of care to improve the care of Children with Complex Medical needs. This involves a second Ward Attending Consultant to focus on their care, supported by a new administrative role and Clinical nurse specialist (CNS) role.

Method The Second Attending Consultant of the week, instead of managing acute medical admissions focusses on these children and families supported by an administrator and the Complex CNS. The model moves away from the daily ward rounds needed by acute patients, with instead twice weekly reviews and a greater focus on coordinating effective Multidisciplinary meetings, addressing psychosocial needs and good communication with families. The changes are based on Qualitative feedback from Staff and Family. Regular evaluation of the effectiveness of the service change has been started alongside a narrative of barriers to change and complications to help inform next steps.

Results Monthly data is collected as indirect measures of improved communication between professionals and has improved from as baseline; time to first Multidisciplinary meeting, time Community teams informed of admission and discharge. Quantitative data regarding length of stay, A\&E attendance, hospital admissions and missed Community appointments due to inpatient stay has been collected as a baseline. Early data shows a reduction in length of stay, data collection for other parameters are planned in January 2020 alongside repeat staff and patient surveys.

Conclusion The paediatric complex care second attending model has enabled improved communication and reduced length of stay for patients with complex medical and social needs

\section{G508 A NATIONAL PICTURE OF CHALLENGES FACED BY PAEDIATRIC UNITS IN DISCHARGE OF CHILDREN WITH MEDICAL COMPLEXITY}

M Salama, RK Shanahan. Children with Medical Complexities Team, Birmingham Children's Hospital, Birmingham, UK

\subsection{6/archdischild-2020-rcpch.433}

Aim The prevalence of children with medical complexity (CMC) has increased in recent decades. CMC often are subject to increased lengths of stays (LOS). Discharge teams within UK paediatric services are more heterogenous as compared to counterpart adult services. Our aim was to explore how discharge for CMC children was facilitated in UK paediatric units.

Method We obtained a list of all UK Paediatric units from the Royal College of Paediatrics and Child Health. We contacted all the units with a freedom of information request for 8 questions. Questions 1-3 were to ascertain knowledge base of numbers of CMC or high LOS inpatients. Questions 4-5 were around non-medical barriers to discharge and Questions 6-8 involved exploration of how discharge planning was facilitated. A second contact was made to non-responders.
Results Of 186 units, 13 duplicate or inactive departments were eliminated. Following the 2 contacts we received a response rate of $86 \%$. Few units were able to reply to the specific question around our CMC definition. There was more clarity around LOS with $71 \%$ of units having $<5$ long stay patients. Of those who replied, just under half the units had patients with non-medical barriers to discharge. Housing, care and commissioning and social barriers were the most common. Tertiary centres were more likely to have non-medical barriers to discharge. Discharge was mostly coordinated by nurses. $8 \%$ of units had a discharge coordinator. There were links to charity support in a large proportion of cases with hospices being most common. Charities such as Wellchild, Roald Dahl and others were mentioned. The most commonly cited paperwork used by this group of children were advanced care plans and hospital passports.

Conclusion Our responses have demonstrated the similarity of challenges faced in supporting CMC and their discharge. CMC numbers are not routinely collected which may mean less visibility of the challenges that are faced. We are seeking to be part of a workstream to share good learning and drive service development for this growing and yet vulnerable group of patients.

\section{G509(P) AN EVALUATION OF 10 YEARS OF CLINICAL PROVISION FOR CHILDREN WITH MEDICALLY UNEXPLAINED SYMPTOMS IN A PAEDIATRIC PSYCHOLOGY SERVICE}

\footnotetext{
1,2S Robinson, ${ }^{1,3} \mathrm{~L}$ McGunnigle, ${ }^{1} \mathrm{~K}$ Golding, ${ }^{3} \mathrm{~L}$ Ah-Wan, ${ }^{1} \mathrm{G}$ Colville. ${ }^{1}$ Paediatric Psychology Service, St Georges University Hospital, London, UK; ${ }^{2}$ Children's Neurosciences, Evelina London Children's Hospital, London, UK; ${ }^{3}$ The School of Psychology, University of Surrey, Guildford, UK
}

\subsection{6/archdischild-2020-rcpch.434}

Aims Medically unexplained symptoms (MUS) are distressing somatic experiences that appear to be of physical origin, but are medically unexplained. Despite evidence from the adult literature that these cases are associated with high utilisation of health care resources, little is known about the impact on services of MUS in children. The aim of this study was to evaluate service use of children with MUS referred to a Paediatric Psychology Service (PPS) at an acute hospital, over a 10 year period, with the view to informing service developments for these patients.

Method Demographic, referral and clinical activity data were available for 268 patients with MUS and 4287 without, referred between 2007 and 2017.

Results Patients with MUS accounted for 4-8\% of referrals annually. Symptoms most commonly reported included unexplained pain, often in the abdomen (33\%), dizziness/fainting/ headaches (21\%), and functional neurological symptoms such as abnormal motor functioning (13\%) and non-epileptic attacks (12\%).

Children with MUS were significantly more likely to be female $\quad(\mathrm{MUS}=56 \%$, non-MUS $=49 \%, \mathrm{p}<0.01)$ and older (MUS=12.5 years, non-MUS=9.2 years, $\mathrm{p}<0.001$ ). In all, $54 \%$ of children with MUS also had a co-occurring medical diagnosis. Patients with MUS required significantly more outpatient clinical sessions than patients without MUS (mean: MUS $=10.7$, non-MUS $=5.4, \mathrm{p}<0.001$ ) and were also more likely to cancel appointments (MUS $=0.7 \%$, non-MUS $=0.4 \%$, $\mathrm{p}<0.01)$. Patient groups did not differ for duration of clinical input or whether clinical objectives were partially/wholly met. 